\title{
Microtubule Motors in Establishment of Epithelial Cell Polarity
}

\author{
Geri Kreitzer ${ }^{1}$ and Monn Monn Myat ${ }^{2,3}$ \\ ${ }^{1}$ Department of Pathobiology, Sophie Davis School of Biomedical Education, City College of New York, \\ The City University of New York School of Medicine, New York, New York 10031 \\ ${ }^{2}$ Department of Biology, Medgar Evers College, Brooklyn, New York 11225 \\ ${ }^{3}$ The Graduate Center, The City University of New York, New York, New York 10016 \\ Correspondence: gkreitzer@med.cuny.edu
}

Epithelial cells play a key role in insuring physiological homeostasis by acting as a barrier between the outside environment and internal organs. They are also responsible for the vectorial transport of ions and fluid essential to the function of many organs. To accomplish these tasks, epithelial cells must generate an asymmetrically organized plasma membrane comprised of structurally and functionally distinct apical and basolateral membranes. Adherent and occluding junctions, respectively, anchor cells within a layer and prevent lateral diffusion of proteins in the outer leaflet of the plasma membrane and restrict passage of proteins and solutes through intercellular spaces. At a fundamental level, the establishment and maintenance of epithelial polarity requires that signals initiated at cellsubstratum and cell-cell adhesions are transmitted appropriately and dynamically to the cytoskeleton, to the membrane-trafficking machinery, and to the regulation of occluding and adherent junctions. Rigorous descriptive and mechanistic studies published over the last 50 years have provided great detail to our understanding of epithelial polarization. Yet still, critical early steps in morphogenesis are not yet fully appreciated. In this review, we discuss how cytoskeletal motor proteins, primarily kinesins, contribute to coordinated modification of microtubule and actin arrays, formation and remodeling of cell adhesions to targeted membrane trafficking, and to initiating the formation and expansion of an apical lumen.

$D^{\mathrm{s}}$ evelopment of morphological and functional polarity underlies many important cellular activities, including directed cell migration, differentiation of numerous cell types, organogenesis, and injury repair. In both single and multicellular animals, the establishment and maintenance of cell polarity requires that microtubule (MT) and actin dynamics, and re- modeling of their respective networks, are coordinated locally in cells. In large part, localized regulation of Rho-family GTPase activity mediates this coordination of MTs and actin, and accommodates formation of specialized subcellular domains (Gundersen et al. 2004; Siegrist and Doe 2007; Li and Gundersen 2008; Wojnacki et al. 2014). As an accompaniment to reg-

Editor: Keith E. Mostov

Additional Perspectives on Cell Polarity available at www.cshperspectives.org

Copyright (C) 2018 Cold Spring Harbor Laboratory Press; all rights reserved; doi: 10.1101/cshperspect.a027896

Cite this article as Cold Spring Harb Perspect Biol 2018;10:a027896 
ulation of MT dynamics, subsets of MTs are locally stabilized along the developing polarity axis and tubulin subunits in these stabilized MTs accumulate biochemically distinct posttranslational modifications (Bre et al. 1987, 1991; Piperno et al. 1987; Bacallao et al. 1989; Pepperkok et al. 1990; Bulinski and Gundersen 1991). These biochemically distinguishable MTs are preferred substrates for the binding and motility of a subset of MT-associated motor proteins (Liao and Gundersen 1998; Kreitzer et al. 1999; Ikegami et al. 2007; Verhey and Gaertig 2007; Dunn et al. 2008; Cai et al. 2009; Konishi and Setou 2009; Hammond et al. 2010; Sirajuddin et al. 2014). In turn, MT remodeling and stabilization repositions many organelles and establishes distinct trafficking routes used by MT motors to direct transport of cytosolic and membrane/secreted proteins to specific domains inside and on the surface of cells (Gundersen 2002).

Epithelial cells line all body surfaces facing the outside world and maintain physiological homeostasis through their characteristic ability to perform vectorial transport of ions and fluid essential to the function of many organs. To do so, apical and basolateral membranes must be structurally and functionally distinct, a feature maintained by tight junctions (TJs) that prevent lateral diffusion of membrane proteins in the outer leaflet of these plasma membrane domains and restrict passage of proteins and solutes through intercellular spaces (Rodriguez-Boulan and Nelson 1989). Attenuation, inhibition, or reversal of epithelial polarity by either direct or indirect means characterize diverse human pathologies, including cancers, cystic diseases, cardiovascular disease, and absorptive and secretory disorders (Wilson 2011; Barrera et al. 2013; Hinck and Nathke 2014; Gandalovicova et al. 2016; Overeem et al. 2016). Although it is known that signals initiated at cell-matrix and cell-cell adhesions trigger local actin and MT reorganization, and that this informs polarized membrane trafficking along MTs, key molecules and regulatory mechanisms orchestrating the structural adaptations that direct functional polarization have not been elucidated fully.

\section{MICROTUBULE MOTORS IN INITIATION OF EPITHELIAL POLARIZATION}

Cell-substratum and cell-cell adhesions are thought to provide spatial landmarks that direct cytoskeletal reorganization, set up secretory targeting patches (e.g., the exocyst), and promote development of distinct transport routes through the cytoplasm leading to apicobasal membrane polarity (Drubin and Nelson 1996; O'Brien et al. 2002; Nelson 2003; Yu et al. 2005; Stehbens et al. 2009; Lee and Streuli 2014). It is not precisely known how these adhesion sites are determined de novo, but the components of these adhesions must be delivered to the plasma membrane by MT-dependent transport, and retained there by establishing interactions with the underlying cytoskeletal network. Failure to establish or loss of functional adhesions is an early hallmark of disease transformation and contributes to attenuation of membrane polarity by obscuring topological cues normally present in intact epithelial tissues. Studies in flies and cultured mammalian epithelia have shown, however, that neither a solid substratum nor adherens junctions (AJs) are necessary for de novo epithelial polarization (Dow and Humbert 2007). Instead, MT-dependent transport of membrane-associated polarity proteins and signaling molecules that promote selective stabilization of MTs is sufficient to polarize even single epithelial cells (Spicer et al. 2003; Baas et al. 2004; Brajenovic et al. 2004; Harris and Peifer 2004, 2005; Trinczek et al. 2004; Theard et al. 2007). Together, these data suggest that nontopological cues for polarity exist and, in fact, may precede adhesion-based, topological cues as stimuli in establishing epithelial polarity.

The nature of putative nontopological polarity cues is unclear as relatively few components of the cytoplasm possess inherent asymmetry. MTs (and actin), however, fall into this class being that they are polarized by their mechanism of assembly into filaments. MT-associated motors, kinesins, and dynein (as well as myosins), are also polarized functionally with respect to their movement toward one end of the filament, and their activity depends on interaction with the polarized cytoskeletal sub- 
strate. Thus, as mediators of targeted protein transport, MT motors can easily be envisioned as fundamental participants in construction of morphological and functional polarity. Indeed, at least for cell-cell contacts, it is known that MT motors are responsible for delivery of transmembrane proteins that form these adhesive contacts through both the biosynthetic and recycling pathways (Mary et al. 2002; Chen et al. 2003; Ivanov et al. 2006; Nekrasova et al. 2011). These newly formed adhesions likely relay signals back to MTs resulting in changes in their organization and the formation of noncentrosomal arrays associated with polarized epithelia. How adhesion molecules are retained at the plasma membrane before establishment of cell adhesions that induce cortical cytoskeletal remodeling is not clear. Most likely, it involves a combination of stochastic or outside-in signaling events leading to capture and stabilization of a subset of MTs. In turn, this reorients membrane-trafficking machineries and directs the delivery of adhesive molecules to the plasma membrane where they form immature contact zones. Signals from these immature contacts subsequently direct more robust cytoskeletal rearrangements, which then stabilize the nascent cell adhesions. This idea that MT motors are key to establishing polarity is supported by studies in Fungi in which MT plus-end-directed kinesins (Tea2, Kip2, and KipA) are necessary for polarized cell growth. Mechanistically, these kinesins localize at growing MT plus ends and at cell ends (Browning et al. 2000; Wedlich-Soldner et al. 2002; Konzack et al. 2005), carry or organize proteins required for local MT capture and stabilization at the cell cortex (Browning et al. 2003; Busch et al. 2004), proteins needed for local actin remodeling (Feierbach et al. 2004; Martin et al. 2005; Snaith et al. 2005), and proteins needed for polarized cell growth (Wedlich-Soldner et al. 2002; Browning et al. 2003; Snaith and Sawin 2003; Steinberg and Fuchs 2004; Takeshita et al. 2008). The MT minus-end-directed motor dynein contributes to polarized cell growth by regulating the position of MT organizing centers, transporting free MTs, tethering MT plus ends to the cortex, and by regulating membrane recycling at the growing ends of cells (Table 1) (Fink and Steinberg 2006).

In metazoa, a role for MT motors in generating cell polarity is less well characterized. Studies in cultured hippocampal neurons show that KIF2A regulates pruning of collateral axon branches by depolymerizing MTs (Homma et al. 2003; Maor-Nof et al. 2013). In contrast, a truncated, constitutively active kinesin- 1 accumulates in the neurite that becomes an axon and may play a role in axon specification (Jacobson et al. 2006). In cultured epithelial cells, kinesin-2 family motors KIF3A/B and KIF17 contribute to regulation of MT dynamics and stabilization, to cytoskeletal remodeling, and to positioning sites of apical membrane insertion and lumen formation (Jaulin and Kreitzer 2010; Acharya et al. 2013, 2016; Boehlke et al. 2013; Li et al. 2014a). Both motors localize to MT plus ends and regulate MT plusend dynamics, but appear to affect epithelial polarity by distinct mechanisms, as highlighted below. Dynein may contribute to establishment of polarity by orienting MTs and tethering MT plus ends at the cortex, most notably at cell-cell adhesions (Ligon and Holzbaur 2007). In this capacity, it may function in a manner similar to its role in capture of astral MTs during mitosis, and in orientation of planar cell polarity (Siegrist and Doe 2005). It is important to note, however, that a role for dynein may not be formative in this mode of polarization. More clear is the role of dynein in animal development, in which it determines oocyte polarity by regulating the delivery of bicoid, and gurken RNAs to the anterior pole and by asymmetric positioning of the nucleus (Brendza et al. 2002; Januschke et al. 2002). Interestingly, kinesin-1 is required for anterior dynein localization and function in oocyte polarization.

\section{KINESINS IN TARGETING CORTICAL CAPTURE SITES FOR MTs}

Remodeling of MTarrays in experimental models of polarity proceeds by a conserved mechanism known as MT search and capture (Goode et al. 2000; Gundersen 2002; Siegrist and Doe 2007). The inherent dynamic instability of MTs 

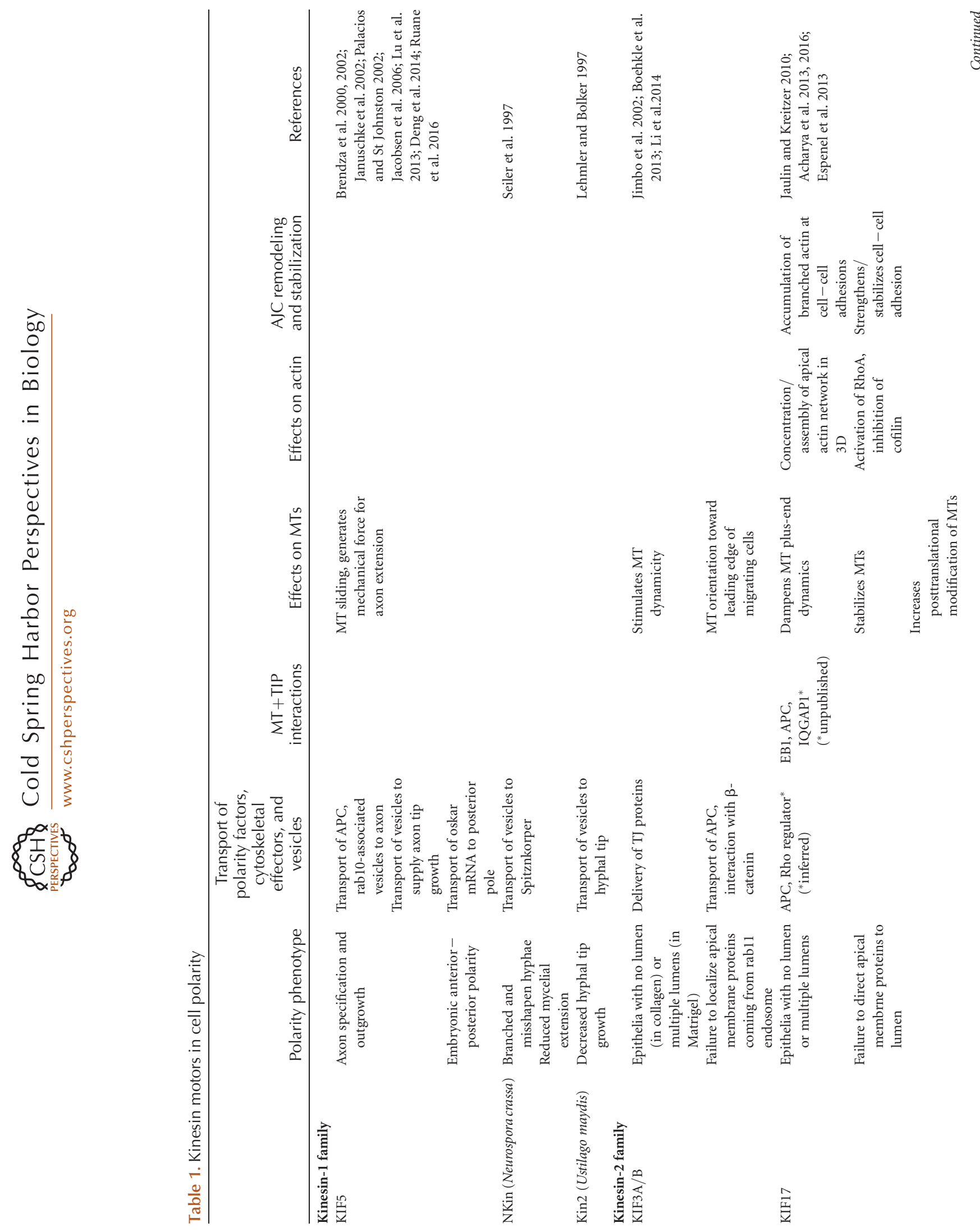


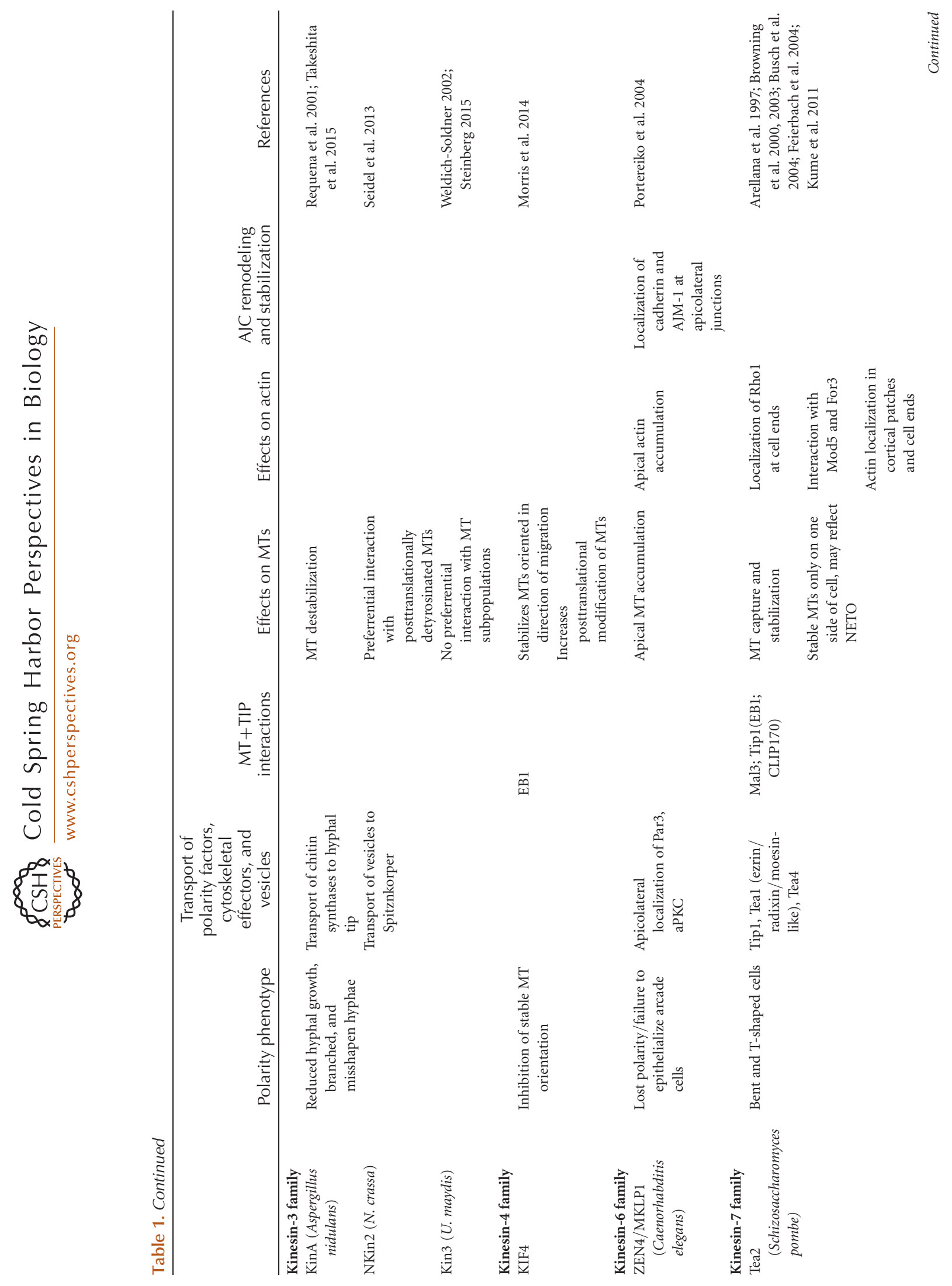



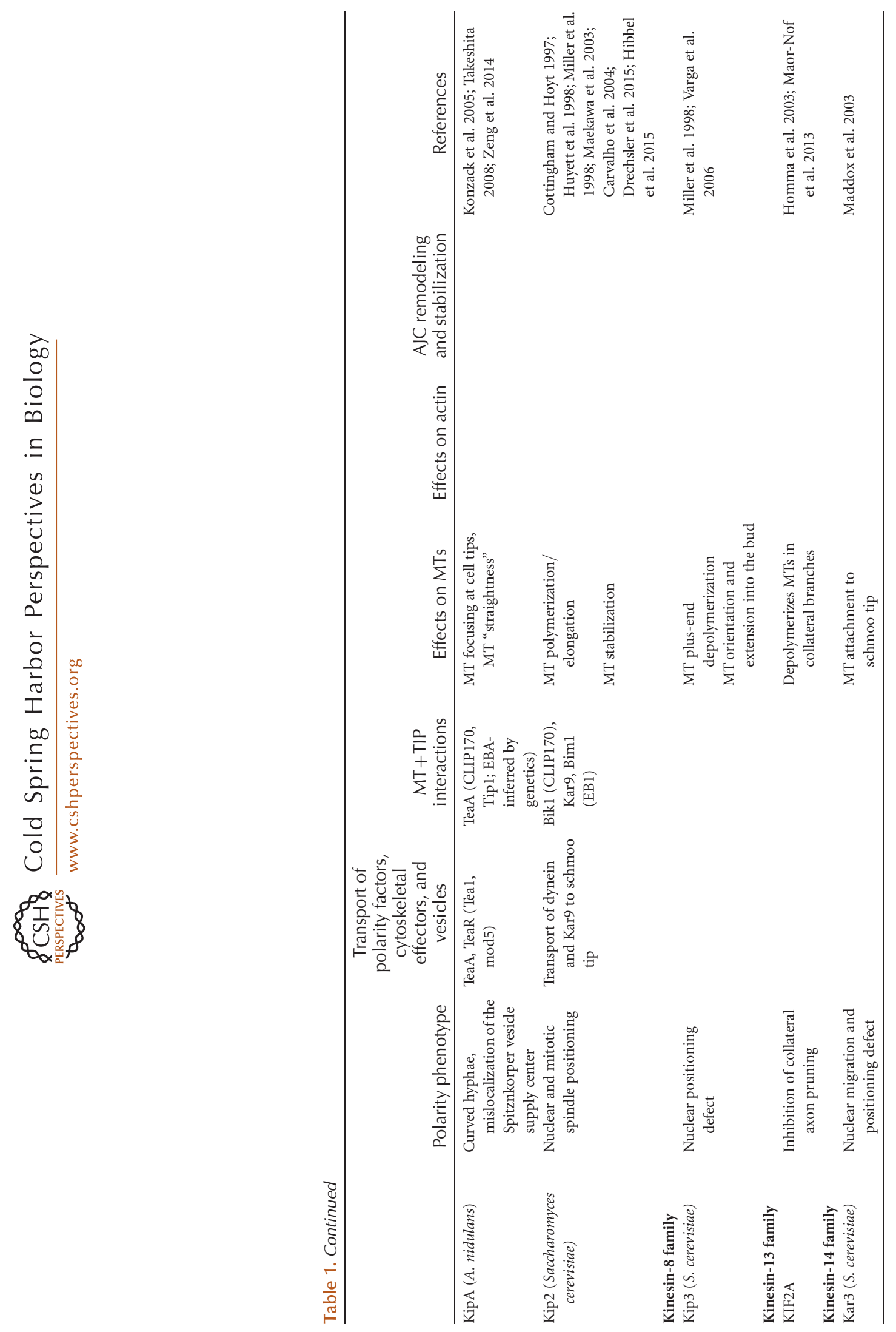
allows for MT plus ends (and proteins associated with them) to search and detect localized signals at the cortex. In response to such cues, a subset of MTs is captured, selectively, and stabilized (Kirschner and Mitchison 1986). The resulting stable, and now polarized, MT arrays accumulate tubulin posttranslational modifications and define an axis along which signals are transduced and provide tracks for the polarized transport of exocytic and endocytic vesicles, proteins complexes, mRNA, and organelles by MT-associated motors.

MT stabilization occurs by a plus-end capping/capture mechanism that prevents addition and loss of tubulin subunits from the polymer (Infante et al. 2000). This capping is dependent on an ATPase activity consistent with that of kinesins. In migrating fibroblasts, MTs oriented in the direction of migration are stabilized selectively in a process mediated by localized signaling through RhoA, mDia1, and integrins (Cook et al. 1998; Palazzo et al. 2001, 2004). In these cells, the kinesin-4 family motor KIF4 (XKLP-1 in Xenopus laevis) interacts with EB1 at MT plus ends, stabilizes a subset of MTs, and is required downstream from lysophosphatidic acid-induced activation of RhoA for MT capture (Morris et al. 2014). In vitro, addition of XKLP-1 to polymerized tubulin inhibits both MT growth and shrinkage, but affects MT dynamics by modifying the MT lattice rather than plus ends (Bringmann et al. 2004). Local activation of Rac and Cdc42 has also been implicated in MT capture at the leading edge of fibroblasts via interactions with the cortical scaffolding protein IQGAP1 and the MT plus-end-associated protein CLIP170 (Fukata et al. 2002). Interestingly, mDial in complex with the MT plus-end-associated protein EB1, interacts with the tumor suppressor adenomatous polyposis coli (APC) (Wen et al. 2004) and APC interacts with IQGAP1 (Watanabe et al. 2004). APC localizes to MT plus ends in fibroblasts and epithelial cells and contributes to MT stabilization in both cell types (Mogensen et al. 2002; Kita et al. 2006; Kroboth et al. 2007).

During epithelial polarization, MTs are further reorganized from centrosomally nucleated, radial arrays into longitudinal bundles (minus ends oriented apically) and arrays of mixed polarity underlying the apical pole and overlying the basal membrane (Bacallao et al. 1989; Gilbert et al. 1991). These noncentrosomal MTs are stabilized and enriched in posttranslationally modified tubulin (Bre et al. 1987, 1991; Pepperkok et al. 1990). In addition, a subset of dynamic MTs is still nucleated at the centrosome and emanates toward the apical and apicolateral membrane domains and serve as tracks for transport and apical delivery of membrane and secreted proteins (Jaulin et al. 2007). The kinase Par1 regulates MT stabilization and reorganization in epithelial cells (Cox et al. 2001; Doerflinger et al. 2003; Cohen et al. 2004), in part by regulating cadherin association with the cortical actin cytoskeleton (Elbert et al. 2006), and thus potentially establishing zones of immature cell-cell adhesion. Although it is clear that cadherin engagement and formation of cell-cell junctions triggers changes in MT dynamics in epithelial cells (Chausovsky et al. 2000; Waterman-Storer et al. 2000; Shtutman et al. 2008), downstream signaling pathways leading to MT reorganization remain obscure. One can easily envision, however, that MT plus ends are selectively captured and stabilized at or near the cell cortex in response to signals transmitted by integrins, cadherins, or membrane-associated signaling complexes.

\section{COORDINATING CYTOSKELETAL REMODELING WITH REMODELING OF CELL-CELL ADHESIONS}

Coordinated remodeling of the cytoskeleton and cell adhesions is key to morphogenetic changes associated with epithelial polarization and function of polarized epithelial cells. Known collectively as the apical junctional complex (AJC), apical junctions couple adjacent cells physically, whereas tight junctions set boundaries between apical and basolateral membranes and control paracellular permeability (Guillot and Lecuit 2013). Components of the AJC are delivered to the membrane by transport along MTs (Mary et al. 2002; Chen et al. 2003; Portereiko et al. 2004; Yanagisawa et al. 2004; Ivanov et al. 2006; Nekrasova et al. 2011) 
and are anchored at adhesive sites by their association with actin and MTadaptors. As cell-cell adhesions mature, signaling molecules that also associate with the AJC induce changes in actin and MT arrays by modifying polymer dynamics and stability (Chausovsky et al. 2000; Mege et al. 2006; Bellett et al. 2009; Ratheesh et al. 2012; Brieher and Yap 2013). Thus, the cytoskeleton affects AJC formation and maturation, and signaling at the AJC reciprocally affects actin and MTs; together, these processes direct morphogenetic responses to numerous cues (Brieher and Yap 2013; Mack and Georgiou 2014). Although many of the molecular components that control formation, dynamics, and remodeling of AJCs and the cytoskeleton are well described, we know little about how these events are coordinated in response to intrinsic and extrinsic cues that affect cell polarity. A logical hypothesis is that molecules that can affect both the cytoskeleton and cell adhesions are key to coordinating cellular remodeling during polarization.

In metazoa, sites of cell-cell contact may be equivalent to growing cell ends in Fungi and, indeed, MT plus ends target to these regions of the plasma membrane where they regulate delivery and turnover of components of AJs by MT motors, as well as cortical actin organization (Pokutta and Weis 2007; Stehbens et al. 2009). The molecular effectors of MT capture and stabilization in epithelia are not yet clearly defined. However, it is interesting to note that the kinesin-2 family motor KIF17, which participates in development of apicobasolateral polarity and lumen formation in MDCK and Caco2 epithelial cells, interacts with both EB1 and APC (Jaulin and Kreitzer 2010). In cells, KIF17 suppresses MT plus-end dynamics and stabilizes MTs. The localization of KIF17 at MT plus ends depends on EB1, which activates KIF17 by relieving its autoinhibited conformation (Espenel et al. 2013). In vitro, EB1 enhances the binding and ATPase activity of KIF17, but is not required to stabilize MTs (Acharya et al. 2013). Importantly, unlike KIF4-mediated MT stabilization in fibroblasts, KIF17, at least in part, appears to act upstream of RhoA in epithelial cells (Acharya et al. 2016). Because KIF17 also localizes at sites of cell-cell adhesion (Acharya et al. 2016), these data suggest KIF17 can act on both MT dynamics and on cortical capture. This idea is consistent with the KIF17-dependent localization of APC to membrane protrusions in epithelial cells (Jaulin and Kreitzer 2010). Precisely how the interaction of KIF17 with these proteins at MT plus ends contributes to downstream polarization events is unknown. RhoA activation by KIF17 appears to occur at sites of cell-cell adhesion, and this induces actin remodeling and stabilization of E-cadherin at these sites by inhibiting the activity of the actin-severing protein cofilin (Acharya et al. 2016). As such, it may act in a manner similar to Tea2 kinesin in Schizosaccharomyces pombe, which interacts with EB1 through its motor domain like KIF17, targets MTs for capture at growing cell ends, and carries kinesin-tail associated cargos that induce actin remodeling and are required for polarized cell growth. It is likely that a cargo carried by KIF17 to sites of cell-cell adhesion similarly modifies the activity of KIF17 toward MT stabilization, actin remodeling, and AJ stability, although this putative cargo has not yet been identified.

Kinesins are additionally used by an alternative pathway to facilitate MT remodeling as epithelial cells become polarized. In this mode, the MT minus-end-binding protein Nezha/ CAMSAP (calmodulin-regulated spectrin-associated protein 3) and MT minus-end-directed KIFC3 localize at AJs (Meng et al. 2008). CAMSAP3 interacts with pleckstrin homology domain protein PLEKHA7 and $\beta$-catenin at AJ and stabilizes noncentrosomal MT minus ends. KIFC3 recruits deubiquitinating enzymes to $\mathrm{AJ}$ protecting $\mathrm{E}$-cadherin from degradation (Meng et al. 2008; Brieher and Yap 2013). CAMSAP3 also regulates local RhoA activity, potentially by recruiting GEF-H1 to noncentrosomal MTs at AJ; this may function in regulating the balance of Rho family GTPases at AJs leading to changes in both MTand actin organization (Nagae et al. 2013). Similarly, the centralspindlin complex containing kinesin MKLP1 interacts with $\alpha$-catenin at AJs and recruits ECT2 RhoGEF to and excludes p190-RhoGAP from these sites to orchestrate a balance of RhoA activity that controls AJ architecture (Ratheesh et al. 2012; Priya et al. 2013). These examples lend 
additional support to the idea that KIF17 carries a cargo involved in coordinating RhoA activities toward cytoskeletal and AJ remodeling.

\section{MICROTUBULE MOTORS IN DIRECTED DELIVERY OF POLARITY PROTEINS}

Kinesins also likely participate in epithelial polarization through their well-established role as cargo transporters (Wozniak et al. 2004; Hirokawa et al. 2009). In addition to maintaining membrane polarity through targeted delivery of apical and basolateral membrane protein cargoes, several kinesins have been implicated in initiation of epithelial morphogenesis based on their interactions with key polarity proteins, including APC, Par3, discs large, and components of AJs and focal adhesions (Cui et al. 2002; Jimbo et al. 2002; Krylyshkina et al. 2002; Asaba et al. 2003; Chen et al. 2003; Nishimura et al. 2004; Shi et al. 2004; Siegrist and Doe 2005; Teng et al. 2005). These studies support the idea that kinesin-mediated transport of polarity proteins may contribute to aspects of cell polarization. Transport of polarity proteins is not limited to kinesins, as dynein is also known to regulate the cortical delivery and localization of polarity proteins, including crumbs, scribble, and pins (Siegrist and Doe 2005, 2007).

\section{MICROTUBULE MOTOR PROTEINS AND LUMEN FORMATION}

A long history documents the importance of MTs and MT remodeling in delivery of apical membrane proteins and in apical lumen formation (Bacallao et al. 1989; Gilbert and Rodriguez-Boulan 1991; Gilbert et al. 1991; Lafont et al. 1994; Ojakian et al. 1997; Noda et al. 2001; Yap and Manley 2001; Jacob et al. 2003; Kreitzer et al. 2003; Cohen et al. 2004; Gervais and Casanova 2010; Jaulin and Kreitzer 2010; Quinones et al. 2011). During the formation of an apical lumen in $3 \mathrm{D}$ cell culture models (seeding single cells in extracellular matrix), apical membrane proteins are retrieved from the exterior, matrixfacing surface by endocytosis and delivered to a rab11-positive vacuolar/endocytic compartment (Schluter et al. 2009; Li et al. 2014b).
As early as at the two-cell stage, recycling of apical markers to a central location at cell-cell contact zones, termed the apical membrane initiation site (AMIS, also known as the preapical patch), specifies the position of a nascent lumen. Coincidentally, basolateral membrane proteins, including cell-cell adhesion components, are excluded from this region allowing expansion of the nascent lumen (Ferrari et al. 2008). Formation of the AMIS can be recapitulated in 2D when cells are cultured in reduced calcium media (Vega-Salas et al. 1987; Gilbert and Rodriguez-Boulan 1991; Ojakian et al. 1997). Under these conditions, cadherin-dependent cell-cell adhesions dissociate and apical membrane proteins mobilize from the cell surface to a large interior structure known as the vacuolar apical compartment (VAC). Actin-rich microvilli are contained in the VAC, but basolateral membrane proteins are excluded, suggesting that this structure is equivalent to an apical endosome. On adding normal calcium media, VACs relocalize to sites of reforming cell-cell contacts in which they first form an AMIS at intercellular contact zones. This is followed by expansion of an intercellular lumen that is subsequently mobilized by an unknown mechanism to the "free" apical surface of monolayer cells (Vega-Salas et al. 1988). Redistribution of VAC membranes to form the intercellular lumen is MT-dependent (Ojakian et al. 1997) and may occur en masse, or by vesiculation and directed transport of vesicles containing these apical membranes. Although it is known that MT depolymerization attenuates or randomizes apical membrane targeting in $2 \mathrm{D}$ cultures and inhibits apical lumen formation in 3D cultures (Gilbert and Rodriguez-Boulan 1991; Ojakian et al. 1997; Kreitzer et al. 2003), the mechanism through which MTs contribute to formation of an apical lumen is not known. Two, nonexclusive mechanisms come to mind: (1) MTs are remodeled as integrins engage the extracellular matrix (Akhtar and Streuli 2013) to position the VAC for apical exocytosis and lumen formation, and (2) MTs are remodeled to generate specialized tracks for MT motor-driven delivery of VAC components to the nascent lumen site, as suggested by Ojakian et al. (1997). 
Although evidence for kinesin and dynein motor proteins in establishing epithelial polarity is accumulating, their role in apical lumen formation during morphogenesis is less well understood. Two recent studies show a role for heterodimeric kinesin-2, KIF3A/B, in lumen formation. Depletion of KIF3A from MDCK cells grown in 3D matrices prevents lumen formation and apical membrane targeting of Kim1. It also inhibits formation of HGF-induced tubular extensions. In two-dimensional culture, KIF3A depletion also stimulates MT dynamics and orients MTs toward the leading edge of migrating cells in wound-healing assays (Boehlke et al. 2013). Although these findings point to a role for KIF3A in lumen formation through its effects on MTs, studies by Li et al. (2014a) suggest that Kinesin-2 regulates lumen formation by controlling apical endosome transport. In support of this, expression of dominant negative KIF3A in MDCK cells prevented the transport of FIP-5, a Rab11-interacting protein, along central spindle MTs. Considered with the selective binding of FIP-5 to KIF3A/B, these data suggest that KIF3A/B contributes to initial stages of lumen formation by transporting apical endosomal vesicles to the correct location between cells.

The homodimeric kinesin-2, KIF17, also plays a role in lumen formation in MDCK cells cultured in 3D matrices (Jaulin and Kreitzer 2010). When KIF17 is depleted from these cells, they fail to form a single lumen and apical markers GP135 and GP114 remain randomly localized on the plasma membrane. KIF17 depletion and overexpression experiments in 2D cultures revealed that KIF17 attenuates MT dynamics, stabilizes MTs, induces cortical MT and actin remodeling by activating RhoA locally, and stabilizes E-cadherin at AJ (Acharya et al. 2013, 2016; Jaulin and Kreitzer 2010). Despite the similar failure of KIF3A- and KIF17-depleted cells to position apical membrane markers and form apical lumens, differences in how these kinesins affect MTs suggest they do not act by entirely equivalent mechanisms. The effects of KIF17 perturbations on MTs are consistent with observed changes in MT dynamics and organization associated with establishment of apicobasolateral polarity; this could directly or indirectly impact recycling and targeting of apical proteins to the nascent lumen. The effects of KIF3A perturbation on MTs and on epithelial sprouting suggest this motor is important for the acquisition of mesenchymal features (Boehlke et al. 2013), and that it participates in lumen formation in its capacity as a motor for transport of Rab11-positive recycling endosomes to the AMIS (Li et al. 2014a).

\section{MICROTUBULE ORGANIZATION AND MOTOR PROTEINS IN ANIMAL TISSUE MORPHOGENESIS}

Although a role for kinesins in lumen formation in animal models is not documented, evidence does exist for dynein in lumen formation in the Drosophila trachea, a network of interconnected tubes that transport oxygen and other gases to target tissues. Larval terminal cells mutant for dynein motor complex genes, Dynein heavy chain, Dynein light intermediate chain, and Glued (encoding Dynactin p150) have thin cytoplasmic branches that fail to fill with air (Schottenfeld-Roames and Ghabrial 2012). Embryo and larval terminal cells mutant for Lissencephaly-1 (Lis-1), encoding a Dynein-associated protein also show defects in lumen formation (Gervais and Casanova 2010; Schottenfeld-Roames and Ghabrial 2012). Dynein in Drosophila tracheal lumen formation likely functions to transport intracellular membrane components to the site of lumen formation.

In the Drosophila embryo, morphogenesis of some epithelial-based organs is also accompanied by dramatic reorganization of the MT cytoskeleton. In invaginating salivary gland cells, the MT cytoskeleton is initially arranged in a dense apical array but undergoes a $90^{\circ}$ reorientation and becomes aligned parallel to the apicobasal axis (Booth et al. 2014). Before MT reorientation, apical MTs are localized close to apical centrosomes; however, after reorientation, most apical MTs are no longer in close proximity to centrosomes. This reorientation positions the minus ends of the longitudinal MTs at the apical membrane in close contact with an apical medial actomyosin network that directs the coordinated and pulsatile con- 
striction of apices during invagination. The switch from centrosomal to noncentrosomal MT growth in salivary gland cells is similar to that reported in tracheal cells. During tracheal cell invagination, MTs that are initially nucleated from $\gamma$-TURC containing centrosomes switch to being nucleated from the apical domain in a two-step process (Brodu et al. 2010). $\gamma$-TURC is released from the centriole in a spastin-dependent manner and is then anchored to the apical membrane through the transmembrane protein Piopio. As embryogenesis proceeds and salivary gland and tracheal cells migrate collectively to form tubes, MTs become progressively stabilized and extend along the apicobasal axis (Brodu et al. 2010; Myat et al. 2015).

A role for noncentrosomal MTs in tissue morphogenesis appears not to be specific to Drosophila. Elongation of the Caenorhabditis elegans embryo is dependent on noncentrosomal MTs functioning with Rho kinase to promote transport of adhesion proteins, such as E-cadherin to the AJs and myotactin to hemidesmosomes (Quintin et al. 2016a,b). Although not documented yet, it is very likely that MT motors transport cargo essential for morphogenesis along these noncentrosomal MTs.

MTs are similarly important for many of the morphogenetic movements that drive neurulation (Cearns et al. 2016). Although the apicobasal cell elongation observed in neurulation as early as the mid-1960s was thought to be MT-dependent, it was only confirmed in 2010 in studies of zebrafish neuroepithelia (Picone et al. 2010). Interkinetic nuclear migration (INM) during neurulation is dependent on MTs in the chick embryo (Spear and Erickson 2012), whereas MTs have only a minor role in INM in the zebrafish retina (Norden et al. 2009). In mice, live imaging studies of brain slices show that dynein and the kinesin-3 motor KIF1A are responsible for INM in radial glial cells, with dynein being responsible for nuclear migration apically toward the ventricle and KIF1A responsible for migration basally toward the pial surface (Tsai et al. 2010). Although there is no additional direct evidence for a role of MT motors in INM, mRNAs encoding the kinesin-1 protein KIF5C are expressed throughout neural tube closure in the chick neuroepithelium (Dathe et al. 2004). In teleosts like the zebrafish, neural progenitor cells initially form a solid rod primordium before cavitating to establish apical polarity and form a lumen at the tissue midline (Cearns et al. 2016). Recent evidence shows a novel mechanism for cell polarization during lumen formation. In the developing zebrafish, neural rod cells assemble a mirror-symmetric MT cytoskeleton around the midline to transport proteins such as Rab11a and Par3 to the site of lumen formation (Buckley et al. 2013). Previous studies suggested Rab1 la to be required for apical membrane trafficking and lumen formation in MDCK cell cysts (Desclozeaux et al. 2008; Bryant et al. 2010) and recent studies in the Drosophila trachea show that apical enrichment of Rab11 depends on dynein-mediated transport (Le Droguen et al. 2015). These studies on Drosophila tracheal development and zebrafish neurulation thus implicate MT and dynein-mediated transport of Rab11 and other regulators of polarization in a key regulatory step in lumen formation. By analogy with evidence obtained in cultured epithelial cells, the importance of MT reorganization and the critical role played by the Rab11-positive apical recycling endosome in model organisms suggest it is also likely that kinesin family motors participate in lumen formation in animals. The genetic tools available in these model organisms combined with highresolution imaging techniques are bound to provide a better understanding of how MT motor proteins regulate lumen formation in vivo in the future.

\section{REFERENCES}

Acharya BR, Espenel C, Kreitzer G. 2013. Direct regulation of microtubule dynamics by KIF17 motor and tail domains. J Biol Chem 288: 32302-32313.

Acharya BR, Espenel C, Libanje F, Raingeaud J, Morgan J, Jaulin F, Kreitzer G. 2016. KIF17 regulates RhoA-dependent actin remodeling at epithelial cell-cell adhesions. $J$ Cell Sci 129: 957-970.

Akhtar N, Streuli CH. 2013. An integrin-ILK-microtubule network orients cell polarity and lumen formation in glandular epithelium. Nat Cell Biol 15: 17-27. 
Arellano M, Duran A, Perez P. 1997. Localisation of the Schizosaccharomyces pombe rholp GTPase and its involvement in the organisation of the actin cytoskeleton. J Cell Sci 110: 2547-2555.

Asaba N, Hanada T, Takeuchi A, Chishti AH. 2003. Direct interaction with a kinesin-related motor mediates transport of mammalian discs large tumor suppressor homologue in epithelial cells. J Biol Chem 278: 8395-8400.

Baas AF, Kuipers J, van der Wel NN, Batlle E, Koerten HK, Peters PJ, Clevers HC. 2004. Complete polarization of single intestinal epithelial cells upon activation of LKB1 by STRAD. Cell 116: 457-466.

Bacallao R, Antony C, Dotti C, Karsenti E, Stelzer EH, Simons K. 1989. The subcellular organization of MadinDarby canine kidney cells during the formation of a polarized epithelium. J Cell Biol 109: 2817-2832.

Barrera MJ, Bahamondes V, Sepulveda S, Quest AF, Castro I, Cortes J, Aguilera S, Urzua U, Molina C, Perez P, et al. 2013. Sjogren's syndrome and the epithelial target: A comprehensive review. J Autoimmun 42: 7-18.

Bellett G, Carter JM, Keynton J, Goldspink D, James C, Moss DK, Mogensen MM. 2009. Microtubule plus-end and minus-end capture at adherens junctions is involved in the assembly of apicobasal arrays in polarised epithelial cells. Cell Motil Cytoskeleton 66: 893-908.

Boehlke C, Kotsis F, Buchholz B, Powelske C, Eckardt KU, Walz G, Nitschke R, Kuehn EW. 2013. Kif3a guides microtubular dynamics, migration and lumen formation of MDCK cells. PLoS ONE 8: e62165.

Booth AJ, Blanchard GB, Adams RJ, Roper K. 2014. A dynamic microtubule cytoskeleton directs medial actomyosin function during tube formation. Dev Cell 29: 562-576.

Brajenovic M, Joberty G, Kuster B, Bouwmeester T, Drewes G. 2004. Comprehensive proteomic analysis of human Par protein complexes reveals an interconnected protein network. J Biol Chem 279: 12804-12811.

Bre MH, Kreis TE, Karsenti E. 1987. Control of microtubule nucleation and stability in Madin-Darby canine kidney cells: The occurrence of noncentrosomal, stable detyrosinated microtubules. J Cell Biol 105: 1283-1296.

Bre MH, Pepperkok R, Kreis TE, Karsenti E. 1991. Cellular interactions and tubulin detyrosination in fibroblastic and epithelial cells. Biol Cell 71: 149-160.

Brendza RP, Serbus LR, Duffy JB, Saxton WM. 2000. A function for kinesin I in the posterior transport of oskar mRNA and Staufen protein. Science 289: 2120-2122.

Brendza RP, Serbus LR, Saxton WM, Duffy JB. 2002. Posterior localization of dynein and dorsal-ventral axis formation depend on kinesin in Drosophila oocytes. Curr Biol 12: 1541-1545.

Brieher WM, Yap AS. 2013. Cadherin junctions and their cytoskeleton(s). Curr Opin Cell Biol 25: 39-46.

Bringmann H, Skiniotis G, Spilker A, Kandels-Lewis S, Vernos I, Surrey T. 2004. A kinesin-like motor inhibits microtubule dynamic instability. Science 303: 1519-1522.

Brodu V, Baffet AD, Le Droguen PM, Casanova J, Guichet A. 2010. A developmentally regulated two-step process generates a noncentrosomal microtubule network in Drosophila tracheal cells. Dev Cell 18: 790-801.
Browning H, Hayles J, Mata J, Aveline L, Nurse P, McIntosh JR. 2000. Tea2p is a kinesin-like protein required to generate polarized growth in fission yeast. J Cell Biol 151: 15-28.

Browning H, Hackney DD, Nurse P. 2003. Targeted movement of cell end factors in fission yeast. Nat Cell Biol 5: 812-818.

Bryant DM, Datta A, Rodriguez-Fraticelli AE, Peranen J, Martin-Belmonte F, Mostov KE. 2010. A molecular network for de novo generation of the apical surface and lumen. Nat Cell Biol 12: 1035-1045.

Buckley CE, Ren X, Ward LC, Girdler GC, Araya C, Green MJ, Clark BS, Link BA, Clarke JD. 2013. Mirror-symmetric microtubule assembly and cell interactions drive lumen formation in the zebrafish neural rod. $E M B O J$ 32: $30-44$.

Bulinski JC, Gundersen GG. 1991. Stabilization of posttranslational modification of microtubules during cellular morphogenesis. Bioessays 13: 285-293.

Busch KE, Hayles J, Nurse P, Brunner D. 2004. Tea2p kinesin is involved in spatial microtubule organization by transporting tiplp on microtubules. Dev Cell 6: 831-843.

Cai D, McEwen DP, Martens JR, Meyhofer E, Verhey KJ. 2009. Single molecule imaging reveals differences in microtubule track selection between Kinesin motors. PLoS Biol 7: e1000216.

Carvalho P, Gupta ML Jr, Hoyt MA, Pellman D. 2004. Cell cycle control of kinesin-mediated transport of Bikl (CLIP-170) regulates microtubule stability and dynein activation. Dev Cell 6: 815-829.

Cearns MD, Escuin S, Alexandre P, Greene ND, Copp AJ. 2016. Microtubules, polarity and vertebrate neural tube morphogenesis. J Anat 229: 63-74.

Chausovsky A, Bershadsky AD, Borisy GG. 2000. Cadherinmediated regulation of microtubule dynamics. Nat Cell Biol 2: 797.

Chen X, Kojima S, Borisy GG, Green KJ. 2003. p120 catenin associates with kinesin and facilitates the transport of cadherin-catenin complexes to intercellular junctions. J Cell Biol 163: 547-557.

Cohen D, Brennwald PJ, Rodriguez-Boulan E, Musch A. 2004. Mammalian PAR-1 determines epithelial lumen polarity by organizing the microtubule cytoskeleton. J Cell Biol 164: 717-727.

Cook TA, Nagasaki T, Gundersen GG. 1998. Rho guanosine triphosphatase mediates the selective stabilization of microtubules induced by lysophosphatidic acid. J Cell Biol 141: $175-185$.

Cottingham FR, Hoyt MA. 1997. Mitotic spindle positioning in Saccharomyces cerevisiae is accomplished by antagonistically acting microtubule motor proteins. J Cell Biol 138: $1041-1053$.

Cox DN, Lu B, Sun TQ, Williams LT, Jan YN. 2001. Drosophila par-1 is required for oocyte differentiation and microtubule organization. Curr Biol 11: 75-87.

Cui H, Dong M, Sadhu DN, Rosenberg DW. 2002. Suppression of kinesin expression disrupts adenomatous polyposis coli (APC) localization and affects $\beta$-catenin turnover in young adult mouse colon (YAMC) epithelial cells. Exp Cell Res 280: 12-23. 
Dathe V, Prols F, Brand-Saberi B. 2004. Expression of kinesin kif5c during chick development. Anat Embryol (Berl) 207: 475-480.

Deng CY, Lei WL, Xu XH, Ju XC, Liu Y, Luo ZG. 2014. JIP1 mediates anterograde transport of Rab10 cargos during neuronal polarization. J NeuroSci 34: 1710-1723.

Desclozeaux M, Venturato J, Wylie FG, Kay JG, Joseph SR, Le HT, Stow JL. 2008. Active Rab11 and functional recycling endosome are required for E-cadherin trafficking and lumen formation during epithelial morphogenesis. Am J Physiol Cell Physiol 295: C545-C556.

Doerflinger H, Benton R, Shulman JM, St Johnston D. 2003. The role of PAR-1 in regulating the polarised microtubule cytoskeleton in the Drosophila follicular epithelium. Development 130: 3965-3975.

Dow LE, Humbert PO. 2007. Polarity regulators and the control of epithelial architecture, cell migration, and tumorigenesis. Int Rev Cytol 262: 253-302.

Drechsler H, Tan AN, Liakopoulos D. 2015. Yeast GSK-3 kinase regulates astral microtubule function through phosphorylation of the microtubule-stabilizing kinesin Kip2. J Cell Sci 128: 3910-3921.

Drubin DG, Nelson WJ. 1996. Origins of cell polarity. Cell 84: 335-344.

Dunn S, Morrison EE, Liverpool TB, Molina-Paris C, Cross RA, Alonso MC, Peckham M. 2008. Differential trafficking of Kif5c on tyrosinated and detyrosinated microtubules in live cells. J Cell Sci 121: 1085-1095.

Elbert M, Cohen D, Musch A. 2006. PAR1b promotes cellcell adhesion and inhibits dishevelled-mediated transformation of Madin-Darby canine kidney cells. Mol Biol Cell 17: 3345-3355.

Espenel C, Acharya BR, Kreitzer G. 2013. A biosensor of local kinesin activity reveals roles of PKC and EB1 in KIF17 activation. J Cell Biol 203: 445-455.

Feierbach B, Verde F, Chang F. 2004. Regulation of a formin complex by the microtubule plus end protein tealp. JCell Biol 165: 697-707.

Ferrari A, Veligodskiy A, Berge U, Lucas MS, Kroschewski R. 2008. ROCK-mediated contractility, tight junctions and channels contribute to the conversion of a preapical patch into apical surface during isochoric lumen initiation. J Cell Sci 121: 3649-3663.

Fink G, Steinberg G. 2006. Dynein-dependent motility of microtubules and nucleation sites supports polarization of the tubulin array in the fungus Ustilago maydis. Mol Biol Cell 17: 3242-3253.

Fukata M, Watanabe T, Noritake J, Nakagawa M, Yamaga M, Kuroda S, Matsuura Y, Iwamatsu A, Perez F, Kaibuchi K. 2002. Rac1 and Cdc42 capture microtubules through IQGAP1 and CLIP-170. Cell 109: 873-885.

Gandalovicova A, Vomastek T, Rosel D, Brabek J. 2016. Cell polarity signaling in the plasticity of cancer cell invasiveness. Oncotarget 7: 25022-25049.

Gervais L, Casanova J. 2010. In vivo coupling of cell elongation and lumen formation in a single cell. Curr Biol 20: 359-366.

Gilbert T, Rodriguez-Boulan E. 1991. Induction of vacuolar apical compartments in the Caco-2 intestinal epithelial cell line. J Cell Sci 100: 451-458.
Gilbert T, Le Bivic A, Quaroni A, Rodriguez-Boulan E. 1991. Microtubular organization and its involvement in the biogenetic pathways of plasma membrane proteins in Caco-2 intestinal epithelial cells. J Cell Biol 113: 275-288.

Goode BL, Drubin DG, Barnes G. 2000. Functional cooperation between the microtubule and actin cytoskeletons. Curr Opin Cell Biol 12: 63-71.

Guillot C, Lecuit T. 2013. Mechanics of epithelial tissue homeostasis and morphogenesis. Science 340: $1185-$ 1189.

Gundersen GG. 2002. Evolutionary conservation of microtubule-capture mechanisms. Nat Rev Mol Cell Biol 3: 296-304.

Gundersen GG, Gomes ER, Wen Y. 2004. Cortical control of microtubule stability and polarization. Curr Opin Cell Biol 16: 106-112.

Hammond JW, Huang CF, Kaech S, Jacobson C, Banker G, Verhey KJ. 2010. Posttranslational modifications of tubulin and the polarized transport of kinesin-1 in neurons. Mol Biol Cell 21: 572-583.

Harris TJ, Peifer M. 2004. Adherens junction-dependent and -independent steps in the establishment of epithelial cell polarity in Drosophila. J Cell Biol 167: 135-147.

Harris TJ, Peifer M. 2005. The positioning and segregation of apical cues during epithelial polarity establishment in Drosophila. J Cell Biol 170: 813-823.

Hibbel A, Bogdanova A, Mahamdeh M, Jannasch A, Storch M, Schaffer E, Liakopoulos D, Howard J. 2015. Kinesin Kip2 enhances microtubule growth in vitro through length-dependent feedback on polymerization and catastrophe. eLife 4: e10542.

Hinck L, Nathke I. 2014. Changes in cell and tissue organization in cancer of the breast and colon. Curr Opin Cell Biol 26: 87-95.

Hirokawa N, Noda Y, Tanaka Y, Niwa S. 2009. Kinesin superfamily motor proteins and intracellular transport. Nat Rev Mol Cell Biol 10: 682-696.

Homma N, Takei Y, Tanaka Y, Nakata T, Terada S, Kikkawa M, Noda Y, Hirokawa N. 2003. Kinesin superfamily protein 2A (KIF2A) functions in suppression of collateral branch extension. Cell 114: 229-239.

Huyett A, Kahana J, Silver P, Zeng X, Saunders WS. 1998. The Kar3p and Kip2p motors function antagonistically at the spindle poles to influence cytoplasmic microtubule numbers. J Cell Sci 111: 295-301.

Ikegami K, Heier RL, Taruishi M, Takagi H, Mukai M, Shimma S, Taira S, Hatanaka K, Morone N, Yao I, et al. 2007. Loss of $\alpha$-tubulin polyglutamylation in ROSA22 mice is associated with abnormal targeting of KIF1A and modulated synaptic function. Proc Natl Acad Sci 104: $3213-3218$.

Infante AS, Stein MS, Zhai Y, Borisy GG, Gundersen GG. 2000. Detyrosinated (Glu) microtubules are stabilized by an ATP-sensitive plus-end cap. J Cell Sci 113: 3907-3919.

Ivanov AI, McCall IC, Babbin B, Samarin SN, Nusrat A, Parkos CA. 2006. Microtubules regulate disassembly of epithelial apical junctions. BMC Cell Biol 7: 12.

Jacob R, Heine M, Alfalah M, Naim HY. 2003. Distinct cytoskeletal tracks direct individual vesicle populations to the apical membrane of epithelial cells. Curr Biol 13: $607-612$. 
Jacobson C, Schnapp B, Banker A. 2006. A change in the selective translocation of the Kinesin-1 motor domain marks the initial specification of the axon. Neuron 49: 797-804.

Januschke J, Gervais L, Dass S, Kaltschmidt JA, Lopez-Schier H, St Johnston D, Brand AH, Roth S, Guichet A. 2002. Polar transport in the Drosophila oocyte requires Dynein and Kinesin I cooperation. Curr Biol 12: 1971-1981.

Jaulin F, Kreitzer G. 2010. KIF17 stabilizes microtubules and contributes to epithelial morphogenesis by acting at MT plus ends with EB1 and APC. J Cell Biol 190: 443-460.

Jaulin F, Xue X, Rodriguez-Boulan E, Kreitzer G. 2007. Polarization-dependent selective transport to the apical membrane by KIF5B in MDCK cells. Dev Cell 13: $511-$ 522.

Jimbo T, Kawasaki Y, Koyama R, Sato R, Takada S, Haraguchi K, Akiyama T. 2002. Identification of a link between the tumour suppressor APC and the kinesin superfamily. Nat Cell Biol 4: 323-327.

Kirschner M, Mitchison T. 1986. Beyond self-assembly: From microtubules to morphogenesis. Cell 45: 329-342.

Kita K, Wittmann T, Nathke IS, Waterman-Storer CM. 2006. Adenomatous polyposis coli on microtubule plus ends in cell extensions can promote microtubule net growth with or without EB1. Mol Biol Cell 17: 2331-2345.

Konishi Y, Setou M. 2009. Tubulin tyrosination navigates the kinesin-1 motor domain to axons. Nat Neurosci 12: 559567.

Konzack S, Rischitor PE, Enke C, Fischer R. 2005. The role of the kinesin motor KipA in microtubule organization and polarized growth of Aspergillus nidulans. Mol Biol Cell 16: 497-506.

Kreitzer G, Liao G, Gundersen GG. 1999. Detyrosination of tubulin regulates the interaction of intermediate filaments with microtubules in vivo via a kinesin-dependent mechanism. Mol Biol Cell 10: 1105-1118.

Kreitzer G, Schmoranzer J, Low SH, Li X, Gan Y, Weimbs T, Simon SM, Rodriguez-Boulan E. 2003. Three-dimensional analysis of post-Golgi carrier exocytosis in epithelial cells. Nat Cell Biol 5: 126-136.

Kroboth K, Newton IP, Kita K, Dikovskaya D, Zumbrunn J, Waterman-Storer CM, Nathke IS. 2007. Lack of adenomatous polyposis coli protein correlates with a decrease in cell migration and overall changes in microtubule stability. Mol Biol Cell 18: 910-918.

Krylyshkina O, Kaverina I, Kranewitter W, Steffen W, Alonso MC, Cross RA, Small JV. 2002. Modulation of substrate adhesion dynamics via microtubule targeting requires kinesin-1. J Cell Biol 156: 349-359.

Kume K, Koyano T, Kanai M, Toda T, Hirata D. 2011. Calcineurin ensures a link between the DNA replication checkpoint and microtubule-dependent polarized growth. Nat Cell Biol 13: 234-242.

Lafont F, Burkhardt JK, Simons K. 1994. Involvement of microtubule motors in basolateral and apical transport in kidney cells. Nature 372: 801-803.

Le Droguen PM, Claret S, Guichet A, Brodu V. 2015. Microtubule-dependent apical restriction of recycling endosomes sustains adherens junctions during morphogenesis of the Drosophila tracheal system. Development 142: $363-374$.
Lee JL, Streuli CH. 2014. Integrins and epithelial cell polarity. J Cell Sci 127: 3217-3225.

Lehmler C, Steinberg G, Snetselaar KM, Schliwa M, Kahmann R, Bolker M. 1997. Identification of a motor protein required for filamentous growth in Ustilago maydis. EMBO J 16: 3464-3473.

Li R, Gundersen GG. 2008. Beyond polymer polarity: How the cytoskeleton builds a polarized cell. Nat Rev Mol Cell Biol 9: 860-873.

Li D, Kuehn EW, Prekeris R. 2014a. Kinesin-2 mediates apical endosome transport during epithelial lumen formation. Cell Logist 4: e28928.

Li D, Mangan A, Cicchini L, Margolis B, Prekeris R. 2014b. FIP5 phosphorylation during mitosis regulates apical trafficking and lumenogenesis. EMBO Rep 15: 428-437.

Liao G, Gundersen GG. 1998. Kinesin is a candidate for cross-bridging microtubules and intermediate filaments. Selective binding of kinesin to detyrosinated tubulin and vimentin. J Biol Chem 273: 9797-9803.

Ligon LA, Holzbaur EL. 2007. Microtubules tethered at epithelial cell junctions by dynein facilitate efficient junction assembly. Traffic 8: 808-819.

Lu W, Fox P, Lakonishok M, Davidson MW, Gelfand VI. 2013. Initial neurite outgrowth in Drosophila neurons is driven by kinesin-powered microtubule sliding. Curr Biol 23: $1018-1023$.

Mack NA, Georgiou M. 2014. The interdependence of the Rho GTPases and apicobasal cell polarity. Small GTPases 5: 10 .

Maddox PS, Stemple JK, Satterwhite L, Salmon ED, Bloom K. 2003. The minus end-directed motor Kar3 is required for coupling dynamic microtubule plus ends to the cortical shmoo tip in budding yeast. Curr Biol 13: 14231428.

Maekawa H, Usui T, Knop M, Schiebel E. 2003. Yeast Cdk1 translocates to the plus end of cytoplasmic microtubules to regulate bud cortex interactions. EMBO J 22: 438-449.

Maor-Nof M, Homma N, Raanan C, Nof A, Hirokawa N Yaron A. 2013. Axonal pruning is actively regulated by the microtubule-destabilizing protein kinesin superfamily protein 2A. Cell Rep 3: 971-977.

Martin SG, McDonald WH, Yates JR III, Chang F. 2005. Tea4p links microtubule plus ends with the formin for3p in the establishment of cell polarity. Dev Cell 8: 479-491.

Mary S, Charrasse S, Meriane M, Comunale F, Travo P, Blangy A, Gauthier-Rouviere C. 2002. Biogenesis of Ncadherin-dependent cell-cell contacts in living fibroblasts is a microtubule-dependent kinesin-driven mechanism. Mol Biol Cell 13: 285-301.

Mege RM, Gavard J, Lambert M. 2006. Regulation of cellcell junctions by the cytoskeleton. Curr Opin Cell Biol 18: 541-548.

Meng W, Mushika Y, Ichii T, Takeichi M. 2008. Anchorage of microtubule minus ends to adherens junctions regulates epithelial cell-cell contacts. Cell 135: 948-959.

Miller RK, Heller KK, Frisen L, Wallack DL, Loayza D, Gammie AE, Rose MD. 1998. The kinesin-related proteins, Kip2p and Kip3p, function differently in nuclear migration in yeast. Mol Biol Cell 9: 2051-2068. 
Mogensen MM, Tucker JB, Mackie JB, Prescott AR, Nathke IS. 2002. The adenomatous polyposis coli protein unambiguously localizes to microtubule plus ends and is involved in establishing parallel arrays of microtubule bundles in highly polarized epithelial cells. J Cell Biol 157: $1041-1048$.

Morris EJ, Nader GP, Ramalingam N, Bartolini F, Gundersen GG. 2014. Kif4 interacts with EB1 and stabilizes microtubules downstream of Rho-mDia in migrating fibroblasts. PLoS ONE 9: e91568.

Myat MM, Rashmi RN, Manna D, Xu N, Patel U, Galiano M, Zielinski K, Lam A, Welte MA. 2015. Drosophila KASHdomain protein Klarsicht regulates microtubule stability and integrin receptor localization during collective cell migration. Dev Biol 407: 103-114.

Nagae S, Meng W, Takeichi M. 2013. Non-centrosomal microtubules regulate $\mathrm{F}$-actin organization through the suppression of GEF-H1 activity. Genes Cells 18: 387-396.

Nekrasova OE, Amargo EV, Smith WO, Chen J, Kreitzer GE, Green KJ. 2011. Desmosomal cadherins utilize distinct kinesins for assembly into desmosomes. J Cell Biol 195: $1185-1203$.

Nelson WJ. 2003. Adaptation of core mechanisms to generate cell polarity. Nature 422: 766-774.

Nishimura T, Kato K, Yamaguchi T, Fukata Y, Ohno S, Kaibuchi K. 2004. Role of the PAR-3-KIF3 complex in the establishment of neuronal polarity. Nat Cell Biol 6: 328334.

Noda Y, Okada Y, Saito N, Setou M, Xu Y, Zhang Z, Hirokawa N. 2001. KIFC3, a microtubule minus end-directed motor for the apical transport of annexin XIIIb-associated Triton-insoluble membranes. J Cell Biol 155: 77-88.

Norden C, Young S, Link BA, Harris WA. 2009. Actomyosin is the main driver of interkinetic nuclear migration in the retina. Cell 138: 1195-1208.

O’Brien LE, Zegers MM, Mostov KE. 2002. Opinion: Building epithelial architecture: Insights from three-dimensional culture models. Nat Rev Mol Cell Biol 3: 531-537.

Ojakian GK, Nelson WJ, Beck KA. 1997. Mechanisms for de novo biogenesis of an apical membrane compartment in groups of simple epithelial cells surrounded by extracellular matrix. J Cell Sci 110: 2781-2794.

Overeem AW, Posovszky C, Rings EH, Giepmans BN, van ISC. 2016. The role of enterocyte defects in the pathogenesis of congenital diarrheal disorders. Disease Model Mech 9: 1-12.

Palacios IM, St Johnston D. 2002. Kinesin light chain-independent function of the Kinesin heavy chain in cytoplasmic streaming and posterior localisation in the Drosophila oocyte. Development 129: 5473-5485.

Palazzo AF, Cook TA, Alberts AS, Gundersen GG. 2001. mDia mediates Rho-regulated formation and orientation of stable microtubules. Nat Cell Biol 3: 723-729.

Palazzo AF, Eng CH, Schlaepfer DD, Marcantonio EE, Gundersen GG. 2004. Localized stabilization of microtubules by integrin- and FAK-facilitated Rho signaling. Science 303: 836-839.

Pepperkok R, Bre MH, Davoust J, Kreis TE. 1990. Microtubules are stabilized in confluent epithelial cells but not in fibroblasts. J Cell Biol 111: 3003-3012.
Picone R, Ren X, Ivanovitch KD, Clarke JD, McKendry RA, Baum B. 2010. A polarised population of dynamic microtubules mediates homeostatic length control in animal cells. PLoS Biol 8: e1000542.

Piperno G, LeDizet M, Chang XJ. 1987. Microtubules containing acetylated $\alpha$-tubulin in mammalian cells in culture. J Cell Biol 104: 289-302.

Pokutta S, Weis WI. 2007. Structure and mechanism of cadherins and catenins in cell-cell contacts. Annu Rev Cell Dev Biol 23: 237-261.

Portereiko MF, Saam J, Mango SE. 2004. ZEN-4/MKLP1 is required to polarize the foregut epithelium. Curr Biol 14: 932-941.

Priya R, Yap AS, Gomez GA. 2013. E-cadherin supports steady-state Rho signaling at the epithelial zonula adherens. Differentiation 86: 133-140.

Quinones GB, Danowski BA, Devaraj A, Singh V, Ligon LA. 2011. The posttranslational modification of tubulin undergoes a switch from detyrosination to acetylation as epithelial cells become polarized. Mol Biol Cell 22: 1045-1057.

Quintin S, Gally C, Labouesse M. 2016a. Noncentrosomal microtubules in C. elegans epithelia. Genesis 54: 229242.

Quintin S, Wang S, Pontabry J, Bender A, Robin F, Hyenne V, Landmann F, Gally C, Oegema K, Labouesse M. 2016b. Non-centrosomal epidermal microtubules act in parallel to LET-502/ROCK to promote C. elegans elongation. Development 143: 160-173.

Ratheesh A, Gomez GA, Priya R, Verma S, Kovacs EM, Jiang K, Brown NH, Akhmanova A, Stehbens SJ, Yap AS. 2012. Centralspindlin and $\alpha$-catenin regulate Rho signalling at the epithelial zonula adherens. Nat Cell Biol 14: 818-828.

Requena N, Alberti-Segui C, Winzenburg E, Horn C, Schliwa M, Philippsen P, Liese R, Fischer R. 2001. Genetic evidence for a microtubule-destabilizing effect of conventional kinesin and analysis of its consequences for the control of nuclear distribution in Aspergillus nidulans. Mol Microbiol 42: 121-132.

Rodriguez-Boulan E, Nelson WJ. 1989. Morphogenesis of the polarized epithelial cell phenotype. Science 245: 718725.

Ruane PT, Gumy LF, Bola B, Anderson B, Wozniak MJ, Hoogenraad CC, Allan VJ. 2016. Tumour suppressor adenomatous polyposis coli (APC) localisation is regulated by both Kinesin-1 and Kinesin-2. Sci Rep 6: 27456.

Schluter MA, Pfarr CS, Pieczynski J, Whiteman EL, Hurd TW, Fan S, Liu CJ, Margolis B. 2009. Trafficking of Crumbs3 during cytokinesis is crucial for lumen formation. Mol Biol Cell 20: 4652-4663.

Schottenfeld-Roames J, Ghabrial AS. 2012. Whacked and Rab35 polarize dynein-motor-complex-dependent seamless tube growth. Nat Cell Biol 14: 386-393.

Seidel C, Moreno-Velasquez SD, Riquelme M, Fischer R. 2013. Neurospora crassa NKIN2, a kinesin-3 motor, transports early endosomes and is required for polarized growth. Eukaryot Cell 12: 1020-1032.

Seiler S, Nargang FE, Steinberg G, Schliwa M. 1997. Kinesin is essential for cell morphogenesis and polarized secretion in Neurospora crassa. EMBO J 16: 3025-3034. 
Shi SH, Cheng T, Jan LY, Jan YN. 2004. APC and GSK-3 $\beta$ are involved in mPar3 targeting to the nascent axon and establishment of neuronal polarity. Curr Biol 14: 20252032.

Shtutman M, Chausovsky A, Prager-Khoutorsky M, Schiefermeier N, Boguslavsky S, Kam Z, Fuchs E, Geiger B, Borisy GG, Bershadsky AD. 2008. Signaling function of $\alpha$-catenin in microtubule regulation. Cell Cycle 7: 23772383.

Siegrist SE, Doe CQ. 2005. Microtubule-induced Pins/G $\alpha$ i cortical polarity in Drosophila neuroblasts. Cell 123: $1323-1335$.

Siegrist SE, Doe CQ. 2007. Microtubule-induced cortical cell polarity. Genes Dev 21: 483-496.

Sirajuddin M, Rice LM, Vale RD. 2014. Regulation of microtubule motors by tubulin isotypes and post-translational modifications. Nat Cell Biol 16: 335-344.

Snaith HA, Sawin KE. 2003. Fission yeast mod5p regulates polarized growth through anchoring of tealp at cell tips. Nature 423: 647-651.

Snaith HA, Samejima I, Sawin KE. 2005. Multistep and multimode cortical anchoring of tealp at cell tips in fission yeast. EMBO J 24: 3690-3699.

Spear PC, Erickson CA. 2012. Interkinetic nuclear migration: A mysterious process in search of a function. Dev Growth Differ 54: 306-316.

Spicer J, Rayter S, Young N, Elliott R, Ashworth A, Smith D. 2003. Regulation of the Wnt signalling component PAR1A by the Peutz-Jeghers syndrome kinase LKB1. Oncogene 22: 4752-4756.

Stehbens SJ, Akhmanova A, Yap AS. 2009. Microtubules and cadherins: A neglected partnership. Front Biosci (Landmark Ed) 14: 3159-3167.

Steinberg G, Fuchs U. 2004. The role of microtubules in cellular organization and endocytosis in the plant pathogen Ustilago maydis. J Microscop 214: 114-123.

Takeshita N, Higashitsuji Y, Konzack S, Fischer R. 2008. Apical sterol-rich membranes are essential for localizing cell end markers that determine growth directionality in the filamentous fungus Aspergillus nidulans. Mol Biol Cell 19: 339-351.

Teng J, Rai T, Tanaka Y, Takei Y, Nakata T, Hirasawa M, Kulkarni AB, Hirokawa N. 2005. The KIF3 motor transports $\mathrm{N}$-cadherin and organizes the developing neuroepithelium. Nat Cell Biol 7: 474-482.

Theard D, Steiner M, Kalicharan D, Hoekstra D, van Ijzendoorn SC. 2007. Cell polarity development and protein trafficking in hepatocytes lacking E-cadherin/ $\beta$-cateninbased adherens junctions. Mol Biol Cell 18: 2313-2321.

Trinczek B, Brajenovic M, Ebneth A, Drewes G. 2004 MARK4 is a novel microtubule-associated proteins/microtubule affinity-regulating kinase that binds to the cellular microtubule network and to centrosomes. J Biol Chem 279: 5915-5923.
Vega-Salas DE, Salas PJ, Rodriguez-Boulan E. 1987. Modulation of the expression of an apical plasma membrane protein of Madin-Darby canine kidney epithelial cells: Cell-cell interactions control the appearance of a novel intracellular storage compartment. J Cell Biol 104: 12491259.

Vega-Salas DE, Salas PJ, Rodriguez-Boulan E. 1988. Exocytosis of vacuolar apical compartment (VAC): A cell-cell contact controlled mechanism for the establishment of the apical plasma membrane domain in epithelial cells. $J$ Cell Biol 107: 1717-1728.

Verhey KJ, Gaertig J. 2007. The tubulin code. Cell Cycle 6: 2152-2160.

Watanabe T, Wang S, Noritake J, Sato K, Fukata M, Takefuji M, Nakagawa M, Izumi N, Akiyama T, Kaibuchi K. 2004. Interaction with IQGAP1 links APC to Rac1, Cdc42, and actin filaments during cell polarization and migration. Dev Cell 7: 871-883.

Waterman-Storer CM, Salmon WC, Salmon ED. 2000. Feedback interactions between cell-cell adherens junctions and cytoskeletal dynamics in newt lung epithelial cells. Mol Biol Cell 11: 2471-2483.

Wedlich-Soldner R, Straube A, Friedrich MW, Steinberg G. 2002. A balance of KIF1A-like kinesin and dynein organizes early endosomes in the fungus Ustilago maydis. EMBO J 21: 2946-2957.

Wen Y, Eng CH, Schmoranzer J, Cabrera-Poch N, Morris EJ, Chen M, Wallar BJ, Alberts AS, Gundersen GG. 2004. EB1 and APC bind to mDia to stabilize microtubules downstream of Rho and promote cell migration. Nat Cell Biol 6: $820-830$.

Wilson PD. 2011. Apico-basal polarity in polycystic kidney disease epithelia. Biochim Biophys Acta 1812: 1239-1248.

Wojnacki J, Quassollo G, Marzolo MP, Cáceres A. 2014. Rho GTPases at the crossroad of signaling networks in mammals: Impact of Rho-GTPases on microtubule organization and dynamics. Small GTPases 5: e28430.

Wozniak MJ, Milner R, Allan V. 2004. N-terminal kinesins: Many and various. Traffic 5: 400-410.

Yanagisawa M, Kaverina IN, Wang A, Fujita Y, Reynolds AB, Anastasiadis PZ. 2004. A novel interaction between kinesin and p120 modulates p120 localization and function. $J$ Biol Chem 279: 9512-9521.

Yap AS, Manley SW. 2001. Microtubule integrity is essential for apical polarization and epithelial morphogenesis in the thyroid. Cell Motil Cytoskeleton 48: 201-212.

Yu W, Datta A, Leroy P, O’Brien LE, Mak G, Jou TS, Matlin KS, Mostov KE, Zegers MM. 2005. $\beta 1$-integrin orients epithelial polarity via Racl and laminin. Mol Biol Cell 16: 433-445.

Zeng CJ, Kim HR, Vargas Arispuro I, Kim JM, Huang AC, Liu B. 2014. Microtubule plus end-tracking proteins play critical roles in directional growth of hyphae by regulating the dynamics of cytoplasmic microtubules in Aspergillus nidulans. Mol Microbiol 94: 506-521. 


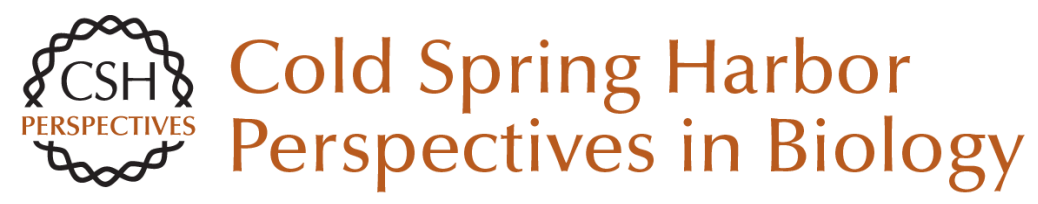

\section{Microtubule Motors in Establishment of Epithelial Cell Polarity}

Geri Kreitzer and Monn Monn Myat

Cold Spring Harb Perspect Biol 2018; doi: 10.1101/cshperspect.a027896 originally published online March 6, 2017

\section{Subject Collection Cell Polarity}

Regulation of Cell Polarity by Exocyst-Mediated Trafficking Noemi Polgar and Ben Fogelgren

Phosphoinositides and Membrane Targeting in Cell Polarity Gerald R. Hammond and Yang Hong

Trafficking lon Transporters to the Apical Membrane of Polarized Intestinal Enterocytes Amy Christine Engevik and James R. Goldenring

Signaling Networks in Epithelial Tube Formation Ilenia Bernascone, Mariam Hachimi and Fernando Martin-Belmonte

Making Heads or Tails of It: Cell-Cell Adhesion in Cellular and Supracellular Polarity in Collective Migration Jan-Hendrik Venhuizen and Mirjam M. Zegers

Laminins in Epithelial Cell Polarization: Old Questions in Search of New Answers Karl S. Matlin, Satu-Marja Myllymäki and Aki Manninen

Epithelial Morphogenesis during Liver Development

Naoki Tanimizu and Toshihiro Mitaka

Targeting the Mucosal Barrier: How Pathogens Modulate the Cellular Polarity Network Travis R. Ruch and Joanne N. Engel
The Crumbs3 Polarity Protein Ben Margolis

Microtubule Motors in Establishment of Epithelial Cell Polarity Geri Kreitzer and Monn Monn Myat

Role of Polarity Proteins in the Generation and Organization of Apical Surface Protrusions Gerard Apodaca

Polarized Exocytosis Jingwen Zeng, Shanshan Feng, Bin Wu, et al.

Regulation of Transporters and Channels by Membrane-Trafficking Complexes in Epithelial Cells

Curtis T. Okamoto

Membrane Transport across Polarized Epithelia Maria Daniela Garcia-Castillo, Daniel J.-F. Chinnapen and Wayne I. Lencer

Mechanisms of Cell Polarity-Controlled Epithelial Homeostasis and Immunity in the Intestine Leon J. Klunder, Klaas Nico Faber, Gerard Dijkstra, et al.

The Biology of Ciliary Dynamics Kuo-Shun Hsu, Jen-Zen Chuang and Ching-Hwa Sung

For additional articles in this collection, see http://cshperspectives.cshlp.org/cgi/collection/

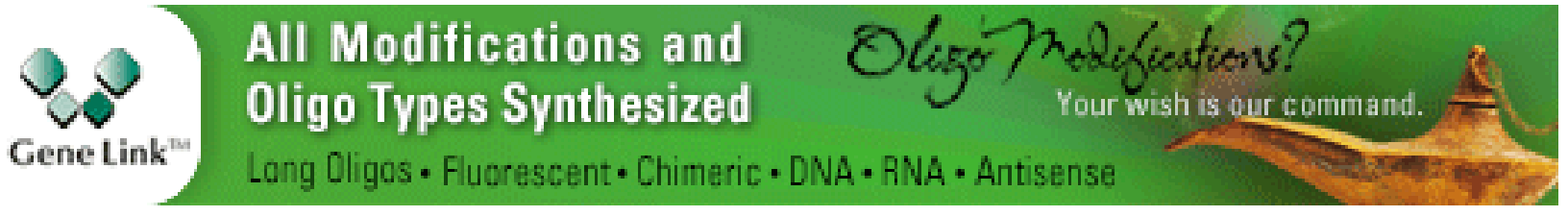

